\title{
O OMBUDSMAN DA BOLSA: \\ HISTÓRIA E IMPORTÂNCIA PARA O PÚBLICO INVESTIDOR
}

Valdir Carlos Pereira Filho'

\section{Resumo}

O Ombudsman do Mercado surgiu como uma iniciativa pioneira da antiga Bolsa de Valores de São Paulo (Bovespa), em 2001. Hoje, seu sucessor, o Ombudsman da B3, funciona como um canal de comunicação da Bolsa com seus públicos de relacionamento, atuando como pilar de governança e proteção aos investidores, prestando um serviço único ao mercado.

Palavras-chave: Ombudsman. Ouvidor. Ouvidoria. Proteção ao investidor. Mercado de capitais.

\section{Abstract}

The Ombudsman do Mercado was as a pioneering initiative of the former São Paulo Stock Exchange (Bolsa de Valores de São Paulo - Bovespa) in 2001. Today, its successor, the B3 Ombudsman, works as a communication channel for the stock exchange with its stakeholders, acting as a pillar of governance and protection of the investors, providing a unique service to the market.

Keywords: Ombudsman. Ombudsman's Office. Investor Protection. Securities Market.

1 Bacharel em Direito pela Faculdade de Direito da USP, LLM pela London School of Economics - LSE do Reino Unido, Doutor em Direito Comercial pela Faculdade de Direito da USP. Professor do Insper Direito. Advogado inscrito na OAB/SP. Superintendente de Ombudsman da B3 - Brasil, Bolsa, Balcão. 


\section{INTRODUÇÃO}

\subsection{Mercado de Capitais, Interesse Público e a Comissão de Valores Mobiliários}

O mercado de capitais é necessário e importante para o desenvolvimento e sustentação das economias dos países, inclusive, como esperado, do Brasil. Este mercado caracteriza-se por ser o local de encontro entre entes superavitários, os poupadores ou investidores, e entes deficitários ou tomadores, ou seja, aqueles que necessitam de recursos financeiros para atender às suas necessidades. No caso do mercado de capitais, os tomadores são, entre outros, companhias abertas, pessoas jurídicas que obtêm autorização regulatória para captar recursos financeiros entre o público em geral e também os veículos de investimentos que, de forma indireta, contribuem para a circulação de riquezas, movimentação da economia e desenvolvimento de atividades variadas, como é caso, por exemplo, dos fundos de investimentos. O fato é que o mercado de capitais é meio ou canal onde a poupança nacional é mobilizada e direcionada para atividades produtivas.

Em razão da mobilização da poupança popular, entendida como o acesso aos recursos que compõem as economias ou reservas da população em geral, o mercado de capitais atrai o interesse estatal. Dessa forma, o mercado de capitais, assim como o mercado financeiro bancário, é alvo de regulação por parte do Estado, a exemplo do que ocorre em praticamente todos os países do mundo. A regulação caracteriza-se pela intervenção do Estado no domínio econômico onde agem entes privados, ou seja, o poder estatal cria regras, fiscaliza, supervisiona, normatiza e sanciona, por meio de autoridades reguladoras (pessoas jurídicas usualmente integrantes do poder executivo), as atividades exercidas pelos entes privados.

No caso do mercado de capitais, o interesse estatal é a proteção dos investidores por meio de adequada divulgação de informações para que haja uma tomada de decisão consciente acerca de efetuar um investimento no mercado e, se já o tiverem feito, em relação à manutenção de seu investimento. A preocupação do Estado, norteadora da regulação estatal, é, sucintamente, assegurar transparência, adequada divulgação de informações, coibir abusos decorrentes de uso indevido de informações não divulgadas (desconhecidas do público em geral) e eficiente formação de preços, ou seja, que reflitam a realidade do mercado e as informações disponíveis a todos.

No Brasil, o mercado de capitais é regulado pela Comissão de Valores Mobiliários (CVM) criada pela Lei 6.385/76. Assim, a CVM exerce o papel de disciplinar o mercado de capitais brasileiro, no regime previsto na lei de sua criação, com poderes sobre seus participantes e as operações e as atividades exercidas nele pelos entes privados. Nesse contexto, a CVM tem ampla gama de atribuições, atividades e ferramentas. Resumidamente, cabe à entidade: (a) administrar os registros (formas de controle e autorização prévia) previstos na Lei 6.385/76 (registro de emissor de valores mobiliários - requisito para uma companhia poder captar recursos da poupança popular no mercado - e registro de oferta pública - autorização prévia para, efetivamente, oferecer ao público, por exemplo, uma ação ou debênture); (b) autorizar o exercício de atividades sujeitas à sua regulação (autorizar, por exemplo, analistas e consultores de valores mobiliários, administradores de carteiras 
ou gestores); (c) criar normas de conduta para os participantes; (d) aplicar penas, sempre observando o devido processo legal e ampla defesa no âmbito administrativo; (e) expedir orientações para o mercado, investidores e emissores de ações ou outros valores mobiliários; e (f) atuar na proteção do mercado e dos investidores em geral.

\subsection{Papel da Bolsa de Valores no Mercado}

Dentro do ecossistema do mercado de capitais regulado pela CVM, existem diversas instituições que desempenham vários papéis e funções visando possibilitar a canalização de recursos da poupança popular para atividades onde tais recursos são necessários. Dessa forma, por exemplo, há os bancos de investimento, que são instituições responsáveis por auxiliar as empresas (companhias emissoras de ações ou debêntures) a decidir o momento certo de acessar o mercado e a estruturar a captação de recursos entre o público investidor; existem as distribuidoras e corretoras de valores que atuam na efetiva formalização dos investimentos do público, ou seja, seus clientes são os investidores que estão dispostos a comprar determinada ação oferecida por uma companhia; há, ainda, entes de caráter reputacional como empresas de auditoria e agências de classificação de risco. Destacam-se aqui as Bolsas de Valores, pois cabem a elas, entre outros e de forma resumida, propiciar ambiente (hoje integralmente eletrônico) para a negociação de ações e outros valores mobiliários. As Bolsas (no Brasil há apenas a B3 - Brasil, Bolsa, Balcão) são o local de circulação e centro de liquidez para as ações e outros valores mobiliários. Assim, qualquer pessoa que tenha investido em uma companhia aberta adquirindo suas ações poderá vendê-las na Bolsa, e quem desejar comprar um determinado papel pode se dirigir também à Bolsa para fazê-lo, sem a necessidade de verificar se a empresa emissora, naquele momento, tem ações disponíveis em oferta; ressalte-se que as ofertas ocorrem em períodos determinados e não continuamente.

Historicamente, as Bolsas de Valores nasceram para ser um polo de liquidez onde afluem os interessados em negociar determinado ativo (títulos, instrumentos financeiros, moedas, mercadorias, produtos agrícolas, participações societárias, títulos de dívida etc.); como resultado, acabaram se tornando um centro de informação sobre bens negociados. As pessoas procuravam as Bolsas por confiarem que o melhor preço possível era o praticado naquele local, já que os interessados no bem negociado lá estavam e tudo o que se referia àquele produto era conhecido e divulgado em tal praça, pois os interessados em tais produtos afluíam para lá.

Para a Bolsa poder cumprir seu papel de centro de liquidez é essencial que existam investidores. Quanto mais investidores disponíveis, mais democrático, maior e mais líquido será o mercado. Dentro desse cenário, todos os perfis de investidores são necessários, grandes e profissionais, nacionais, estrangeiros e pequenos poupadores, sobretudo os investidores individuais pessoas físicas.

Em linha com os objetivos regulatórios da CVM, a Bolsa sempre procurou trazer segurança para os investidores pessoas físicas, já que, sob alguns aspectos, precisam de uma atenção diferenciada, diferentemente dos grandes investidores ou profissionais. Inovadora na América Latina, a Bovespa instituiu, em abril de 2001, o Ombudsman do Mercado. 


\section{A FIGURA DO OMBUDSMAN NO MERCADO DE CAPITAIS BRASILEIRO}

\subsection{O Ombudsman do Mercado: Pioneirismo na Proteção aos Investidores}

O Ombudsman do Mercado nasceu como um canal de comunicação da então Bovespa com os investidores. É importante fazer uma digressão para explicar o contexto da criação do Ombudsman do Mercado pela Bovespa, pois o cenário era bem diferente do atual e nos permitirá, posteriormente, compreender a evolução do Ombudsman do Mercado daquele período até o Ombudsman da B3 de hoje.

Em 2001, a Bovespa era a principal e única Bolsa em efetiva operação no Brasil com mercado de ações. Sua forma jurídica era a de uma associação civil sem fins lucrativos, semelhante a um clube. Seus sócios eram as corretoras de valores, que detinham títulos patrimoniais, sendo, portanto, membros e "donos" da Bolsa. A Bovespa criou o Ombudsman do Mercado e atribuiu-lhe como função primordial "atender demandas de investidores relacionadas ao processo de negociação, liquidação e custódia de títulos e valores mobiliários e que configurem questionamentos contra agentes de mercado credenciados ou reconhecidos pela Bovespa, e buscar uma solução de consenso para a controvérsia existente entre ambos"2.

O Ombudsman do Mercado nasceu para buscar solução consensual de conflitos entre investidores e corretoras em relação a operações e negócios realizados em Bolsa, sendo que a Bovespa decidiu oferecer esse serviço e canal de comunicação aos investidores de forma voluntária e no contexto de seu programa de expansão e popularização do mercado de capitais entre os investidores pessoas físicas. Foi uma decisão estratégica da Bovespa sem interferência ou exigência regulatória, normativa ou legal. Para tal feito, a Bovespa se inspirou na experiência anterior e de sucesso da Bolsa de Madri, que contava com um Protector del Inversor, figura que exerce papel semelhante ao atribuído ao Ombudsman do Mercado, ainda existente na Espanha3.

A importância da decisão da Bovespa reside no fato de que na época da criação do Ombudsman do Mercado, abril de 2001, as corretoras de valores, membros da Bolsa e por meio das quais os investidores realizavam suas operações, não eram obrigadas a ter Ouvidorias próprias. Essa obrigação viria com a edição da Resolução n 3.477 do Conselho Monetário Nacional (CMN), em 26 de julho de 2007. Portanto, a Bovespa possibilitou aos investidores, seis anos antes do CMN, um canal para solução consensual de conflitos. Assim, na prática, a Bovespa instituiu uma Ouvidoria para as corretoras de valores para o que se referisse às operações em Bolsa que, seguramente, eram e são uma parte relevante de seus negócios. Esse modelo vigorou inalterado até 2008.

\subsection{O Ombudsman da BM\&FBovespa: Evolução de Governança}

Com a evolução do mercado e seguindo tendências internacionais, a Bovespa, em 2007, passou por um processo de desmutualização, ou seja, transformou-se em uma pessoa jurídica com fins

2 Artigo $1^{\circ}$ do Regulamento do Ombudsman do Mercado da Bovespa vigente à época.

3 Disponível em: http://www.bolsamadrid.es/esp/BMadrid/Protector/Protector11.aspx. Acesso em: 20 jun. 2018.

176 | Revista Científica da Associação Brasileira de Ouvidores/Ombudsman - Ano 2 - nº 2 - 2019 
lucrativos. A Bovespa deixou de ser uma associação civil para se tornar uma sociedade anônima de capital aberto.

No ano seguinte, em maio de 2008, a Bovespa se uniu à Bolsa de Mercadorias \& Futuros BM\&F, que também já havia se desmutualizado, sendo também uma companhia aberta, e assim nasceu a BM\&FBovespa - Bolsa de Valores, Mercadorias e Futuros. Naquele momento, o Ombudsman do Mercado continuou seu trabalho, mas com a estrutura de supervisão de mercados da Bolsa: a BM\&FBovespa Supervisão de Mercados (BSM), pois era a BSM a responsável, entre outras funções, por fiscalizar as corretoras e, eventualmente, se pertinente, indenizar investidores lesados por meio do seu Mecanismo de Ressarcimento de Prejuízos 4 .

Em 2010, novamente como uma decisão estratégica e de governança, a BM\&FBovespa decidiu que o Ombudsman do Mercado deveria ter seu escopo de atuação ampliado e não ficar restrito a demandas de investidores contra corretoras: o Ombudsman do Mercado passou a ser o Ombudsman da BM\&FBovespa, tornando-se a Ouvidoria da Bolsa, isto é, a Ouvidoria da empresa BM\&FBovespa. O Ombudsman da BM\&FBovespa manteve sua função original de auxiliar investidores em suas demandas contra corretoras e passou as receber demandas contra a própria Bolsa, ou seja, tornou-se um canal de comunicação com todos os stakeholders da BM\&FBovespa.

\subsection{O Ombudsman da B3: Continuidade e Desafios}

Em março de 2017, finalmente, a BM\&FBovespa combinou suas atividades com a Cetip S.A. - Mercados Organizados (Cetip), dando origem à B3 - Brasil, Bolsa, Balcão (B3). Assim, o Ombudsman da BM\&FBovespa passou a ser denominado Ombudsman da B3.

O Ombudsman da B3 é o canal de comunicação da B3 com o público externo, com os participantes de negociação, liquidação e custódia, investidores dos mercados administrados pela B3, profissionais da imprensa, instituições públicas e privadas, emissores de valores mobiliários listados na B3, empresas fornecedoras e acionistas da própria B3. Suas atribuições são: (a) receber, registrar, instruir, analisar e dar tratamento formal e adequado a reclamações, sugestões, elogios e solicitações dos públicos que se relacionam com a Companhia e dos usuários de seus produtos e serviços; (b) prestar esclarecimentos necessários e dar ciência aos reclamantes acerca do andamento de suas demandas; (c) informar aos reclamantes o prazo previsto para a resposta final; (d) encaminhar resposta conclusiva para a demanda dos reclamantes; e (e) propor medidas corretivas ou de aprimoramento de procedimentos e rotinas, em decorrência da análise das reclamações recebidas ${ }^{5}$.

Hoje, então, o Ombudsman da B3 desempenha a função de uma Ouvidoria clássica, reativa, recebendo demandas dos interessados, mantendo também sua função de origem, que é auxiliar na busca de solução consensual de conflitos entre investidores e as corretoras das quais são clientes; também é por meio delas que acessam os mercados e sistemas de negociação da B3. Estas duas funções coexistem e se complementam, pois a B3 tem interesse no desenvolvimento do mercado

4 Disponível em: http://www.bsm-autorregulacao.com.br/ressarcimento-de-prejuizos/como-funciona. Acesso em: 20 jun. 2018.

5 Item 1.1 do Regulamento do Ombudsman da BM\&FBovespa, atualmente Ombudsman da B3. 
e o Ombudsman da B3, no exercício de sua função original, atende anseios e expectativas de um tipo de investidor importante: a pessoa física. Por outro lado, por ser uma companhia aberta e uma empresa que é referência e indutora de boas práticas, é esperado que a B3 tenha um canal de comunicação de Ouvidoria disponível para seus públicos de relacionamento.

O Ombudsman da B3, seguindo as melhores práticas, tem autonomia e independência, sendo um dos pilares de governança da empresa; trabalha sob absoluta confidencialidade e sigilo, e a função é desempenhada por funcionário com cargo de liderança vinculado ao executivo máximo da companhia, no caso, o Presidente da B36 .

\section{A RELAÇÃO ENTRE OMBUDSMAN, INVESTIDORES E CORRETORAS}

O contexto do mercado de capitais atual (realidade do Ombudsman da B3) difere muito daquele de 2001 (momento de criação do Ombudsman do Mercado). Uma das diferenças é que as corretoras, como já vimos, devem obrigatoriamente ter Ouvidorias, tanto por disposição do CMN atualmente prevista na Resolução do $\mathrm{CMN} \mathrm{n}^{\circ}$ 4.433/15 (Resolução 4.433), norma em vigor e atual sucessora da Resolução 3.477, assim como por determinação da CVM contida na Instrução CVM $n^{0}$ 529/2012 (ICVM 529). Entretanto, verificamos que, apesar de todas as corretoras contarem com componente organizacional de Ouvidoria, os investidores seguem procurando o Ombudsman da B3.

Diversas vezes os investidores vêm até o Ombudsman da B3 sem ter feito contato com o canal de Ouvidoria das corretoras. Aliás, a maior parte das demandas do Ombudsman da B3 decorre de sua função original ${ }^{7}$, ou seja, a maioria refere-se a investidores reclamando contra instituições das quais são clientes. Para ilustrar, tomemos os números de 2017 , em que $70 \%$ das demandas foram referentes às corretoras e $6 \%$ apenas contra a B3 $3^{8}$. Em outras palavras, o Ombudsman da B3 atuou como Ouvidoria da B3 como empresa, no interesse de seus stakeholders diretos, em apenas 6\% dos casos apresentados, em 2017, ao Ombudsman.

O perfil das demandas apresentadas ao Ombudsman da B3, ou sua distribuição considerando a instituição demandada, tem possíveis explicações. A primeira decorreria de razões históricas: como o Ombudsman do Mercado surgiu antes das corretoras terem suas Ouvidorias, os investidores se acostumaram a recorrer ao Ombudsman da Bolsa quando em situação de conflito com as corretoras. Essa justificativa poderia explicar o fato de diversos investidores terem procurado a B3 sem antes tentar resolver o assunto diretamente com a corretora, ou terem feito apenas contato

6 Em linha com as melhores práticas para a função e atividade preconizadas no Manual de Boas Práticas Ouvidorias Brasil da Abrarec - Associação Brasileira das Relações Empresa Cliente. Disponível em: http://abrarec.com.br/ wp-content/uploads/2015/07/Vs_pb.pdf. Acesso em: 20 jun. 2018.

7 Conforme divulgado no Relatório de Anual de Atividades do Ombudsman da B3 referente a 2017. Disponível em: http://www.bmfbovespa.com.br/pt_br/institucional/ombudsman/relatorios/. Acesso em: 20 jun. 2018.

8 Além disso, houve $24 \%$ de demandas contra instituições financeiras, notadamente bancos, que prestam serviços de agente escriturador de companhias abertas ou de agentes de custódia. De qualquer forma, refere-se, também, à demanda apresentada ao Ombudsman da B3 contra instituições diferentes da B3, de forma análoga às demandas contra corretoras.

178 | Revista Científica da Associação Brasileira de Ouvidores/Ombudsman - Ano 2 - nº $2-2019$ 
com o primeiro nível de atendimento (SAC, central de atendimento ou congênere). Outra explicação decorre da confiança que os investidores, sobretudo pessoas físicas, têm na Bolsa. Em outras palavras, por acreditarem na competência e imparcialidade da B3 como instituição, preferem recorrer ao Ombudsman dela em detrimento das Ouvidorias das corretoras. Este fato também explica casos em que o investidor recorre à Ouvidoria da corretora e, insatisfeito com a resposta, apresenta a mesma demanda ao Ombudsman da B3. Entretanto, o Ombudsman não tem poder de supervisão sobre as corretoras, assim como não conduz procedimentos administrativos e nem arbitra ou determina ressarcimentos ou pagamento de qualquer tipo. Portanto, estando a decisão da Ouvidoria da corretora correta e fundamentada, o Ombudsman apenas informa ao investidor que não há o que ser feito. Para o investidor, essa confirmação da Bolsa é suficiente para ele ter certeza, então, que a resposta recebida está adequada, aceitando desse modo o encerramento do caso. Em uma situação hipotética oposta, caso a reposta da Ouvidoria da corretora estivesse, na visão do Ombudsman, equivocada, este poderia - e deveria - tentar convencer a corretora a rever sua posição, mas, importante frisar, sem poder impor, reformar a decisão de ofício, obrigar ou penalizar.

Do ponto de vista do investidor, atualmente, há, então, a estrutura de Ouvidoria da corretora da qual ele é cliente, regida pelas normas do CMN e CVM, sendo a Ouvidoria um componente organizacional obrigatório; e há o Ombudsman da B3, este instituído por liberalidade da Bolsa com o intuito de ser um canal de comunicação e orientação auxiliar para os investidores. A coexistência e relacionamento do Ombudsman da B3 com as Ouvidorias das corretoras são pautados por cooperação e parceria. Não há qualquer tipo de sobreposição ou concorrência, ao contrário, o que ocorre é o diálogo buscando a melhor forma de solucionar o caso ou esclarecer o investidor demandante.

Como o Ombudsman da B3 não tem poderes de supervisão, de fiscalização ou de sanção, o atendimento e resposta às suas solicitações por parte das corretoras é inteiramente voluntário. Entretanto, a adesão e colaboração das corretoras é praticamente unânime. Tal situação decorre do fato de que o compromisso do Ombudsman é com o investidor e com o bom funcionamento do mercado, sob sigilo absoluto. Dessa forma, eventual demanda, apesar de envolver um terceiro externo à corretora, no caso o Ombudsman da B3, não traz consequência como punição, multa, registro negativo ou qualquer outro resultado que poderia advir se o terceiro alheio envolvido fosse o regulador ou entidade supervisora, como a CVM ou BSM respectivamente. Há um interesse em resolver a demanda na esfera do Ombudsman da B3, pois, apesar de ser fora da corretora, há o sigilo e não há risco de desdobramentos regulatório-sancionadores, que são a regra quando se envolve alguma entidade com poder-dever de fiscalizar. Caso o Ombudsman se depare com alguma irregularidade grave ou ilicitude, deverá comunicá-la à área de supervisão da Bolsa competente para que seja apurada, mas não fará, até por não ter elementos probatórios, encaminhamento formal ou denúncia e nem encaminhará evidências documentais eventualmente recolhidas, pois esse não é seu objetivo. Seu papel diante de irregularidades é dar ciência para que investiguem, pois não pode acobertar ou ser conivente. Entretanto, na prática, situações assim são bastante raras, ou seja, não é comum o Ombudsman se deparar com ocorrência sobre a qual precisaria alertar supervisores. 


\section{CONSIDERAÇÕES FINAIS}

Pelo exposto, o investidor do mercado de capitais, no que se refere a operações de Bolsa, conta com uma estrutura de proteção ampla: (a) o regulador, CVM; (b) a B3 com seu Ombudsman e a estrutura de autorregulação da BSM; e (c) as Ouvidorias das corretoras.

Importante destacar que as opções mencionadas não se excluem e cada uma tem seu escopo bem definido, mas com o objetivo comum, entre outros, de proteção e orientação aos investidores.

O que caracteriza e diferencia o Ombudsman da B3 é sua atuação pautada pelo sigilo, isenção e autonomia. Em outras palavras, conta com a reputação e estrutura da B3, mas age auxiliando o investidor com espírito independente de colaboração e podendo ser um representante ou porta-voz do investidor. Vale ressaltar que o Ombudsman recebe diversas demandas que não configuram reclamação ou conflito, mas, apenas, pedidos de informações ou esclarecimentos. Dessa forma, outro papel relevante desempenhado, em decorrência da vontade dos investidores, é aquele de orientação e educação. Sempre que possível, as respostas do Ombudsman têm um componente educacional ou de orientação.

Assim, seja como Ouvidor da B3 ou como auxiliar de investidores na solução de conflitos com corretoras, o Ombudsman tem o compromisso de detectar oportunidades de melhorias e apresentar propostas para a B3. Todas as demandas, independentemente de seu conteúdo ou tipo, são oportunidades de aprender e evoluir. O ideal de Ouvidoria é intrínseco, assim, ao Ombudsman da B3, apesar de ter uma natureza ou função sui generis: o Ombudsman atua como Ouvidor da instituição à qual está vinculado e também como facilitador de diálogo e auxiliar na solução de conflitos entre stakeholders da Bolsa, e faz isso legitimado pela sua independência e a confiança que o mercado, em especial os investidores, deposita nele.

\section{REFERÊNCIAS}

ABRAREC. Manual de boas práticas Ouvidorias Brasil. Disponível em: <http://abrarec.com.br/wp-content/ uploads/2015/07/Vs_pb.pdf>. Acesso em: jun. 2018.

AGGARWAL, Reena. Demutualization and Corporate Governance of Stock Exchanges. Journal of Applied Corporate Finance, v. 15, Spring 2002. Disponível em SSRN: <https://ssrn.com/abstract=327360> ou <http://dx.doi.org/10.2139/ ssrn.327360>. Acesso em: jun. 2018.

CENTURIÃO, Alberto. Ombudsman: a face da empresa cidadã: como e por que instalar uma Ouvidoria. São Paulo: Educator, 2003.

COMISSÃO DE VALORES MOBILIÁRIOS. O mercado de valores mobiliários brasileiro. 3. ed. Rio de Janeiro: CVM, 2014.

PEREIRA FILHO, Valdir C. Ouvidoria no mercado financeiro é ferramenta para redução de litígios. In Consultor Jurídico, 29 de junho de 2015. Disponível em: <https://www.conjur.com.br/2015-jun-29/valdir-filho-ouvidoria-mercado-financeiro-ajuda-reduzir-ligitios>. Acesso em: jun. 2018. 